\title{
AN INVESTIGATION INTO RADIATION LEVELS ASSOCIATED WITH DISMANTLING THE KOREA RESEARCH REACTOR
}

\author{
GEUN-SIK CHOI, HEE REYOUNG KIM* and MOON HEE HAN \\ Korea Atomic Energy Research Institute \\ Yuseong, Daejeon 305-353, Korea \\ *Corresponding author. E-mail : kimhr@kaeri.re.kr \\ Received October 15, 2009 \\ Accepted for Publication May 31, 2010
}

We confirmed that the dismantling of two research reactors with thermal power of $2 \mathrm{MW}_{\text {th }}$ and $100 \mathrm{~kW}_{\text {th }}$, respectively, reveals no significant difference between the radiation levels of the research reactor site and the surrounding environment far away from it, from the radiation level aspect. Radiation dose and radioactivity were measured at monitoring points around the research reactor site of the Korea Atomic Energy Research Institute (KAERI) in Seoul and comparison points $0.5 \mathrm{~km}$ to 3.3 $\mathrm{km}$ from the site. To grasp trends in the radiation levels during dismantling from the end of 2002 to the end of 2007, the gamma radiation dose rate, the accumulated dose, and the radioactivity of the strontium, tritium, and gamma isotopes were statistically treated and estimated. The averages of these items between the two groups, the research reactor site and comparison points, were assessed by applying a T-test with a significance level of 0.05 . P-values found by using the T-test were from 0.12 to 0.83 where the values were much higher than the significance level. As a result, no difference was observed between the radiation levels at the research reactor site and at the comparison points by this T-test. This study showed that dismantling activity of the Korea Research Reactor of the Seoul site did not expose the public or the environment to harmful levels of radiation.

KEYWORDS : Radiation level, Korea Research Reactor, Dismantling, Radioactivity, T-test

\section{INTRODUCTION}

The Korea Atomic Energy Research Institute (KAERI) operates three research reactors as domestic nuclear research installations. Of these, a new research reactor has been operated at the Daejeon site for radioisotope research, training, medicine and other uses since the two research reactors (Korea Research Reactors $1 \& 2, \mathrm{KRR}-1 \& 2$ ) at the Seoul site were stopped in 1995. Also, based on the domestic Atomic Energy Act, an environmental radiation monitoring (ERM) process has been implemented to promote nuclear safety by tracing environmental changes caused by the operation of these three nuclear installations. In general, environmental radiation monitoring is carried out for social, political and technical reasons such as compliance with statutory legislation; an assessment of radiation exposure to the public; public reassurance and information; research; attempts to establish preoperational radiation levels; and assistance in emergency situations [1-6]. In fact, public concern has been related to radiation field variations that may be caused by a nuclear installation in operation and its effect on the environment. In addition, public attention has recently focused on the dismantling of the research reactor at the Seoul site. The site whose research reactor was dismantled from 2003 to 2007 is in the capital city, with a dense population area. As a result, public requests for information on radiation levels related to its dismantling have increased. This paper includes a statistical analysis on the environmental radiation monitoring results of the Korea Research Reactor site in Seoul and the comparison points for the five years since the start of its dismantling. We undertook this evaluation to determine whether dismantling the research reactor caused any difference in radiation levels between the on-site and comparison points or not.

\section{MEASUREMENTS AND METHOD}

Environmental radiation monitoring includes measurements of an external gamma radiation dose rate by an environmental radiation monitor and the accumulated dose by thermoluminescence dosimeters (TLDs). Also, it covers environmental radioactivity in samples of the soil, sediment, water, air particulate and pine needles. In Fig. 1 (a), the research reactor site is within $100 \mathrm{~m}$ of the radius from the center of the dismantled nuclear reactors. On the site, the gamma radiation (dose rate and accumulated dose) is measured to the east and west about $10 \mathrm{~m}$ from the KRR-1 \& 2 buildings, and at the front gate of the site. In 
addition, the accumulated dose is measured near the auxiliary buildings including waste storage facilities. The environmental sampling points are located near the reactor and the auxiliary buildings as seen in Fig. 1 (a). As for the surface water, it is not sampled on site but near the Seoul National University of Technology, $0.6 \mathrm{~km}$ from the Korea Research Reactor site in Seoul because of the lack of on-site water sampling capacity. In Fig. 1 (b), the comparison points for the radioactivity samples such as soil, sediment and others were chosen according to the results of environmental impact assessments on the dismantling of the KRR-1 \& 2 reactors. In the assessment on the dismantling of the KRR-2, the annual individual effective dose was $5.87 \times 10^{-6} \mathrm{mSv}$ for the maximum exposure group by calculation at the site boundary (about $100 \mathrm{~m}$ from the research reactor) [7]. This is $5.87 \times 10^{-4} \%$ of $1 \mathrm{mSv}$, the dose limit for the public. So, the comparison points were selected at points at least five times as far away as the distance between the site boundary and the reactor for more negligible effect. The comparison point on the gamma radiation and surface water is Kwangwoon University, which has no nuclear installation, $3.3 \mathrm{~km}$ from the dismantled reactor site. The sampling points of the soil and the sediment, which are the Korea Cancer Center Hospital and Seoul National University of Technology, respectively, are $0.7 \mathrm{~km}$ away. Also, those of the air particulate and the pine needles are about $0.5 \mathrm{~km}$ away. Table 1 shows an outline of environmental monitoring of the radiation and radioactivity for the Korea Research

\section{Reactor in Seoul.}

\subsection{External gamma radiation measurements}

Environmental gamma radiation levels were measured at ten points around the research reactor site (on-site, which are within $100 \mathrm{~m}$ from the reactor buildings) and a comparison point by using a pressurized ion chamber (Reuter Stokes, RSS-1012) where the chamber was installed $1.2 \mathrm{~m}$ above ground [8]. The hourly averages by year were obtained, and the data unit used at that time was $\mu \mathrm{R}$ per unit of time $(\mu \mathrm{R} / \mathrm{h})$, which had not been converted to the air kerma rate or the effective dose rate [9]. The accumulated dose was measured at a height of $1 \mathrm{~m}$ from the ground to supplement the measurement by the environmental gamma radiation monitoring. The accumulated dose was measured quarterly at nine points around the research reactor site (on-site), and a comparison point, which is $3.3 \mathrm{~km}$ from the reactor buildings, by using TLDs (Harshaw, TLD 4500). The quarterly averaged data had a unit of $\mathrm{mR} /$ quarter. The combined uncertainty of the measurements was computed by using the standard deviations based on a series of measurements over the period [10].

\subsection{Environmental sampling and radioactivity analyses}

Soil, sediment, water, air particulate and pine needle samples were taken at the on-site and comparison points [8]. Four soil samples were taken biannually according to

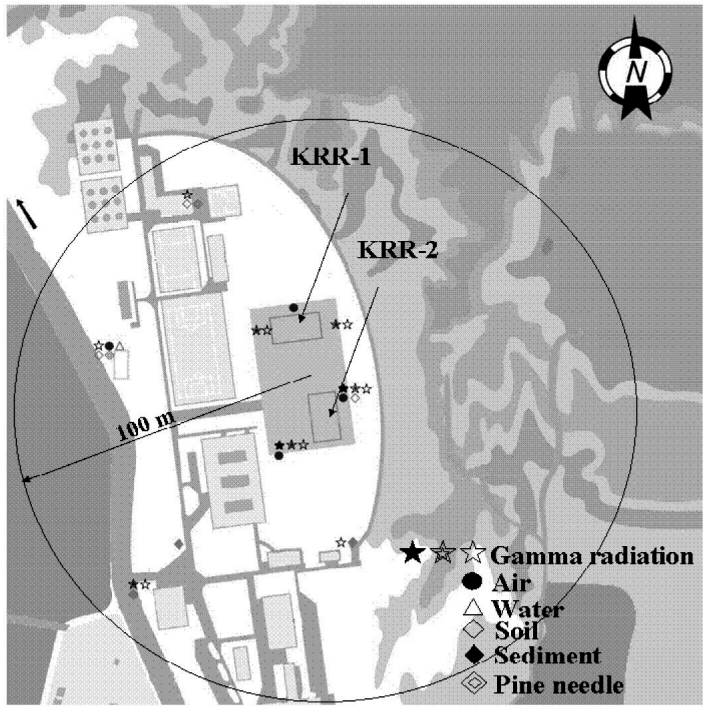

Fig. 1. (a)

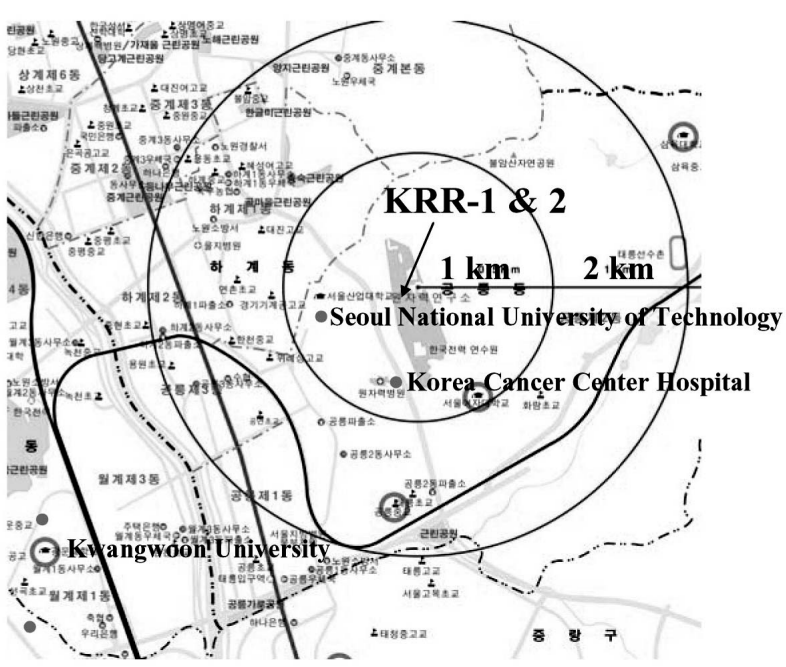

Fig. 1. (b)

Fig. 1. (a) Site of the Dismantled Research Reactors in Seoul, and (b) Points Used to Compare Radiation or Radioactivity Levels with Those of the Research Reactor Site 
the monitoring program, which used three on-site sampling points and one from the comparison point. Sediment was sampled quarterly at three on-site points and a comparison point. Water samples were classified into two types, surface and ground water. First of all, the surface water samples were taken monthly from a comparison point and the ground water samples quarterly from one on-site point, respectively. In particular, the surface water sampling was conducted to investigate the possibility of the effluence and diffusion of the radioactivity due to the dismantling of the KRR-2 over a multi-year period. The air particulate samples were analyzed monthly at four on-site points and a comparison point, respectively. The number of sampling points in the sediment, where the samples were analyzed quarterly, was three and one for the on-site and the comparison point, respectively. On the other hand, pine needles as a bio sample were sampled biannually from one on-site point and the comparison point each. In the sampling and analysis, the gamma radioisotopes included the artificial nuclides such as ${ }^{134} \mathrm{Cs},{ }^{137} \mathrm{Cs},{ }^{131} \mathrm{I},{ }^{60} \mathrm{Co},{ }^{51} \mathrm{Cr}$, ${ }^{59} \mathrm{Fe},{ }^{54} \mathrm{Mn},{ }^{22} \mathrm{Na},{ }^{152} \mathrm{Eu},{ }^{154} \mathrm{Eu}$, and the natural ones such as ${ }^{40} \mathrm{~K}$ and ${ }^{7} \mathrm{Be}$. In fact, the concrete of the reactor containment and the graphite of the thermal column were supposed to contain the artificial nuclides including ${ }^{137} \mathrm{Cs},{ }^{60} \mathrm{Co},{ }^{152} \mathrm{Eu}$, ${ }^{154} \mathrm{Eu},{ }^{3} \mathrm{H}$ by a neutron activation for a few decades. Therefore, those nuclides were analyzed to find the particular environmental impact from the dismantling activity of the KRR-2.

The concentration of gamma radioisotopes was measured by using a gamma spectrometer (ORTEC, HPGe detector with MCA). A low-level counter (BERTHOLD, LB53090) and a liquid scintillation counter (WALLAC, Quantulus 1220) were used for the radioactivity of ${ }^{90} \mathrm{Sr}$ and ${ }^{3} \mathrm{H}$, respectively. On the other hand, the gross alpha and beta radioactivity were measured by using a low- background counting system (OXFORD, Tennelec LB5100IIW). In the same way as the external gamma radiation measurements were conducted, a computation of the combined uncertainty of the measurements was carried out [10].

\subsection{Estimation of averages between research reactor site and comparison site}

For the present estimation with a finite number of samples, a statistical T-test was employed to determine whether a noticeable difference existed between the two groups, an average of the research reactor site (on-site) and the comparison site [11-12]. The T-test is the hypothesis test method determining the equality of mean values of the two groups with the number of samples smaller than 30 in general. The sample size was smaller than 30 in this analysis. First of all, the distribution of the population groups for the two groups was assumed to be a normal distribution, although the possibility of an asymmetry could be contained in the samples themselves. The twotail test was accomplished to assess if the averages of the two population groups would be the same or not by using Equation (1) in the case of the same population variance and Equation (2) in the case of a different population variance.

$$
\begin{gathered}
T=\frac{x_{1}-x_{2}}{s \sqrt{\frac{1}{n_{1}+\frac{1}{n_{2}}}} \quad, s^{2}=\frac{\left(n_{1}-1\right) s_{1}^{2}+\left(n_{2}-1\right) s_{2}^{2}}{\left(n_{1}-1\right)+\left(n_{2}-1\right)}} \\
T=\frac{x_{1}-x_{2}}{\sqrt{\frac{s_{1}^{2}}{n_{1}}+\frac{s_{2}^{2}}{n_{2}}}}
\end{gathered}
$$

\begin{tabular}{|c|c|c|c|c|}
\hline \multirow{2}{*}{ Classification } & \multirow{2}{*}{ Sample } & \multicolumn{2}{|c|}{ Sampling points } & \multirow{2}{*}{ Nuclides } \\
\hline & & On-site & Comparison point & \\
\hline \multirow[t]{2}{*}{ Radiation } & Dose rate & 5 & 1 & $\gamma$-radiation \\
\hline & Cumulative dose & 9 & 1 & $\gamma$-radiation \\
\hline \multirow[t]{6}{*}{ Radioactivity } & Soil & 3 & 1 & ${ }^{90} \mathrm{Sr}, \gamma$-isotope \\
\hline & Sediment & 3 & 1 & $\gamma$-isotope \\
\hline & Surface water & - & 1 & ${ }^{3} \mathrm{H}, \gamma$-isotope \\
\hline & Ground water & 1 & - & ${ }^{3} \mathrm{H}, \gamma$-isotope \\
\hline & Air particulate & 3 & 1 & $\gamma$-isotope \\
\hline & Pine needle & 1 & 1 & $\gamma$-isotope \\
\hline
\end{tabular}

Table 1. Environmental Monitoring Summary 
where $\mathrm{x}_{1}, \mathrm{~s}_{1}$, and $\mathrm{n}_{1}$ denote the average, standard deviation and the number of samples for the research reactor site, and $\mathrm{x}_{2}, \mathrm{~s}_{2}$ and $\mathrm{n}_{2}$ for the comparison points, respectively. The significance level of 0.05 , which corresponds to a confidence level of $95 \%$, was taken and the P-value from the T-test was compared with it. Here, the $\mathrm{P}$-value measures how far the observed test statistic (T) is from the null hypothesis, assuming that it is true. Therefore, the larger the P-value, the less evidence we have against the null hypothesis. That is, when the $\mathrm{P}$-value is larger than the significance level $(\alpha)$, the null hypothesis is not rejected.
On the other hand, in this study, the comparison between the statistical dispersions of the two groups was carried out by using the simple F-test and the dispersion parameter from it was employed to the T-test implementation.

\section{RESULTS AND DISCUSSION}

The measurements represented values less than the minimum detection activity (MDA) for all artificial gamma isotopes of the samples of the air particulate, the surface

Table 2. Annual Average Radiation Levels by Using ERM

\begin{tabular}{ccc}
\hline Year & Dismantling research reactor site & Comparison point \\
\hline 2003 & $13.3 \pm 0.68$ & $13.8 \pm 0.55$ \\
2004 & $13.6 \pm 0.82$ & $14.1 \pm 0.43$ \\
2005 & $15.3 \pm 3.66$ & $14.2 \pm 0.69$ \\
2006 & $13.7 \pm 1.77$ & $13.9 \pm 0.77$ \\
2007 & $13.7 \pm 0.66$ & $14.0 \pm 0.80$ \\
P-value & & 0.83 \\
\hline
\end{tabular}

Table 3. Annual Average Radiation Levels by Using TLD

\begin{tabular}{ccc}
\hline Year & Dismantling research reactor site & Comparison point \\
\hline 2003 & $25.0 \pm 2.23$ & $25.3 \pm 2.50$ \\
2004 & $25.7 \pm 3.50$ & $26.8 \pm 2.90$ \\
2005 & $27.2 \pm 3.82$ & $29.0 \pm 3.17$ \\
2006 & $26.2 \pm 3.74$ & $28.3 \pm 4.01$ \\
2007 & $25.7 \pm 3.26$ & $26.9 \pm 2.96$ \\
P-value & & 0.12 \\
\hline
\end{tabular}

Table 4. Annual Average Levels of Strontium $\left({ }^{90} \mathrm{Sr}\right)$ in the Soil

\begin{tabular}{ccc}
\hline Year & Dismantling research reactor site & Comparison point \\
\hline 2003 & $0.59 \pm 0.278$ & $0.57 \pm 0.055$ \\
2004 & $0.98 \pm 0.107$ & $0.91 \pm 0.020$ \\
2005 & $0.84 \pm 0.081$ & $0.92 \pm 0.215$ \\
2006 & $1.34 \pm 0.303$ & $1.10 \pm 0.135$ \\
2007 & $1.08 \pm 0.107$ & $1.09 \pm 0.191$ \\
P-value & & 0.77 \\
\hline
\end{tabular}


water and the ground water at the on-site or comparison points. Also, the tritium concentration showed values less than the MDA for the surface and the groundwater. For measurements of the gamma radioisotopes, the soil and pine needle samples had concentration values more than the MDA only for ${ }^{137} \mathrm{Cs}$ in the on-site and the comparison points. And the external gamma radiation and strontium also represented certain values more than the MDA values in the on-site and the comparison points. Therefore, the average comparison of the two sites (on-site and comparison points) was carried out for the results without MDA values. Tables 2 to 6 represented the results of the statistical T-test analyses of the environmental radiation and radioactivity at both sites for the corresponding period.

In the computation of the combined uncertainty, the error from the measuring activity at the various points and times was dominant while that from the equipment system was negligible [13]. In the present analysis, the P-values were between 0.13 and 0.83 where the values are 2.4 to 16.6 times as high as 0.05 , the present significance level. Therefore, the averages for the dismantled research reactor site and comparison points were not thought to have significant differences at least at the $95 \%$ confidence level.

In this study, the T-test was applied as one of the statistical methods to estimate the differences in the averages between the two groups. The significance level for this analysis was 0.05 , corresponding to the confidence interval of $95 \%$, which is the level generally used in statistical test. In fact, by calculation, the different tests can show different results, even the opposite estimation result, when the $\mathrm{P}$-value is close to the significance level of 0.05 (for example, 0.051, 0.048...). But, the P-values by this T-test were 2.4 to 16.6 times higher than the significance level, 0.05. Therefore, the P-values are thought to be at least higher than 0.05 even if the different tests give different figures for the P-values. As a result, it is thought that the estimation will not be changed significantly by different tests.

In Tables 2 and 3, the average values of the radiation dose will include the effect by non-working hours. This effect can cause relatively low dose-rate values due to mathematical average calculations over a year in spite of the possibility of relatively high activity during dismantling working hours. But, the measured environmental radiation exposure dose rate by using a real-time environmental radiation monitor actually represented the background levels in both cases of the dismantling working and nonworking hours in the on-site, indicating that no particular difference will exist between the annual averaged values and the working hour-based ones.

Table 5. Annual Average Levels of Cesium $\left({ }^{137} \mathrm{Cs}\right)$ in the Soil

\begin{tabular}{ccc}
\hline Year & Research reactor site & Comparison point \\
\hline 2003 & $5.09 \pm 3.456$ & $1.88 \pm 0.962$ \\
2004 & $2.53 \pm 2.137$ & $1.33 \pm 0.665$ \\
2005 & $1.74 \pm 1.205$ & $2.25 \pm 0.212$ \\
2006 & $1.82 \pm 0.898$ & $1.65 \pm 0.495$ \\
2007 & $2.66 \pm 2.726$ & $1.30 \pm 1.389$ \\
P-value & & 0.13 \\
\hline
\end{tabular}

Table 6. Annual Average Levels of Cesium $\left({ }^{137} \mathrm{Cs}\right)$ in the Pine Needles

\begin{tabular}{ccc}
\hline Year & Research reactor site & Comparison point \\
\hline 2003 & $0.058 \pm 0.0226$ & $0.103 \pm 0.0403$ \\
2004 & $0.027 \pm 0.0120$ & $0.079 \pm 0.0806$ \\
2005 & $0.048 \pm 0.0311$ & $0.100 \pm 0.0117$ \\
2006 & $0.170 \pm 0.0670$ & $0.140 \pm 0.1260$ \\
2007 & $0.091 \pm 0.0687$ & $0.096 \pm 0.0510$ \\
P-value & & 0.39 \\
\hline
\end{tabular}


On the other hand, the atmospheric diffusion, which is a meteorological factor, can affect the effective dose for the on-site and comparison points. In fact, it is one of the important reasons to cause differences in spite of the same sampling points. But the level of the exposure dose rates was similar to that of the background level and the radioactivity was much smaller even in the on-site measurements as seen in Tables 2 to 6 . So, it is not thought that meteorological factors will greatly affect the results.

\section{CONCLUSION}

The present analyses for the external gamma radiation and the radioactivity of the beta nuclides like ${ }^{3} \mathrm{H},{ }^{90} \mathrm{Sr}$ and the gamma nuclides like ${ }^{131} \mathrm{I},{ }^{137} \mathrm{Cs},{ }^{152} \mathrm{Eu}$ during the dismantling showed that the P-values were much higher than the significance level at a $95 \%$ confidence level. Also, no water sample represented radioactivity in the two groups. Therefore, there was not thought to be a difference in the radiation levels at the Korea Research Reactor site of Seoul and the comparison points. Ultimately, the study indicates that dismantling the KRR2 did not expose its surroundings to harmful levels of radiation.

\section{REFERENCES}

[1] A. R. Ware and C. W. Fern, "The Need and Requirements for Environmental Monitoring”, Nuclear Europe 3 (4), (1988).
[2] W. Peters, "Radiation monitoring and local authorities", ATOM 378, (1988).

[ 3 ] D. van Lith, "Dutch Environmental Monitoring for Nuclear Emergencies", Nuclear Europe 5 (6), (1989).

[4] Peter Shebell and Kevin M. Miller, "Analysis of Eighteen Years of Environmental Radiation Monitoring Data", Environmental International, 22, Suppl. 1, (1996).

[ 5 ] H. Kimura, et al., "Monitoring of environmental radiation and radionuclides around nuclear fuel cycle facilities from 1989 to 1995", J. of Radioanalytical and Nuclear Chemistry, 226 (1-2), (1997).

[6] Thomas G. Hobbs, "Environmental Radiation Monitoring at NBS/NIST From 1960 Through 2000", J. of Research of the National Institute of Standards and Technology, 106 (5), (2001).

[ 7 ] Kee Jung Jung, et al, "Environmental Impact Assessment Report”, KAERI/TR-1655/2000, KAERI report, (2000) (in Korean).

[ 8 ] Choi Geun Sik, et al, "Environmental Radiation Monitoring around the Nuclear Facilities", KAERI/RR-2979/2008, KAERI report, (2008) (in Korean).

[ 9 ] Herman Cember, Introduction to Health Physics, 3rd ed., p. 181, McGraw-Hill, New York, (1996).

[10] Moffat, "Describing the uncertainties in experimental results", Experimental Thermal and Fluid Science, 1, (1988).

[11] Kim, Yong Tae, et al, "A Study on Teaching Method of TwoSample Test for Population Mean Difference", J. Korea Soc. Math. Ed. Ser. A: The Mathematical Education, 45 (2), (2006) (in Korean).

[12] Murray, Theory and Problems of Statistics, p. 188, Double Six Press, (1981).

[13] Eurachem, "Quantifying Uncertainty in Analytical Measurement”, EURACHEM/CITAC Guide, (2000). 